\title{
Unusual Finding of Oxytocin in Illicit Liquor Samples by HPTLC
}

\author{
B P. MORE ${ }^{* 1}$, B B. DOUNDKAR ${ }^{2}$ and R.B.TOCHE ${ }^{3}$ \\ ${ }^{1}$ Regional Forensic Science Laboratory, Opposite Vidyut Nagar, \\ Dindori Road, Nasik-422004, M.S., India \\ ${ }^{2}$ Directorate of Forensic Science Laboratories, Kalina, \\ Santacruz east, Mumbai-98 M.S., India \\ ${ }^{3}$ Department of Chemistry, KTHM College, Nashik-422002 M.S., India \\ bhaumore1@gmail.com
}

Received 25 September 2013 / Accepted 8 November 2013

\begin{abstract}
The oxytocin (cyclic octapeptide hormone) also called as love hormone, is a mammalian neurohypophysical hormone that acts primarily as a neuromodulator in the brain and causes anxiety. The oxytocin is also having side effects causes proved to be harmful to human being and hence the use of oxytocin is prohibitated by the Government. The investigation showed that for monitor gain illicit add oxytocin in liquors to increase effect of alcohol. The study was under taken to find out harmful adulterants in the suspected liquors. The present method include HPTLC using glacial acetic acid: water: methanol and dichloromethane (1:6:30:70) as a mobile phase and phosphomolybdotungstic a specific chromogenic spray reagent. This approach is the simplest tool for identification of adulterant used in illicit liquor samples.
\end{abstract}

Keywords: Illicit liquor, Oxytocin, HPTLC, Forensic lab, Phosphomolybdotungstic

\section{Introduction}

Under section Mumbai prohibition act 1965 the forensic science laboratories in Maharashtra state is regularly receiving number of illicit liquor samples. Recent studies have begun to investigate oxytocin in liquors. Oxytocin is a cyclic octapeptide hormone released by the posterior pituitary and showing Uterotonic and galactogenic activity. It is chemically- $L$ hemi-cystinyl- $L$-tyrosyl- $L$-isoleucyl- $L$-glutaminyl- $L$-asparaginyl- $L$-hemi-cystinyl- $L$-propyl$L$-leucylglycinamide. It consists of 20 member ring with five amino acids- cysteine, tyrosine, isoleucine, glutamine and asparagines, further three amino acids, proline, leucine and glycinamide. [Klaus Florey, Analytical profile of drug substances] oxytocin is involved in the contraction of uterus and milk ejection in receptive mammals. In the brain oxytocin is classically viewed as primarily involved in the milk let down reflex and in the stimulation of uterine smooth muscle during parturition. The oxytocin plays various roles in human body such as orgasm, social recognition, pair bonding, anxiety and mental behavior. 


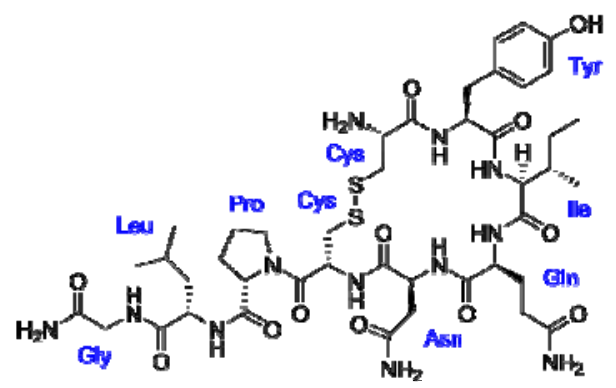

Figure 1. Structure of oxytocin

New inventions prove that when oxytocin (Figure 1) is injected into cows, there is a result over production of milk. The excess of oxytocin is found to be present in milk. Side effects of oxytocin include nausea, vomiting, severe allergic reactions, bleeding after child birth, abnormal heart beats, high blood pressure and and rupture of the uterus, headache, abdominal pain, drowsiness etc. Oxytocin may be important for the inhibition of the brain regions associated with behavioral control, fear and anxiety, thus allowing orgasm to occur and also functions to protect against stress. Meta-analyses conducted in 2003 demonstrated that it can alleviate mood and reduce stress with a good efficiency.

Illicit liquor unlicensed distilleries or small production units operate clandestinely. The raw material used are cheap and available locally include sugarcane, rice, or coarse grains. Similar to those in country liquor, but since they evade legal quality controls the alcohol concentration in their products is less and hence they do adulteration to get alcohol effect. It is common to find samples containing up to $56 \%$ alcohols. Sometime methylated spirit was added, which causes mass poisoning. License alcohols are charged heavy duty and they are expensive. On illicit liquors are inexpensive as they are unlicensed and not paid any duty considerably less expensive and hence are popular. In India illicit liquor production and marketing is like a cottage industry. House fermentation and distillation is also common in some parts of the country.

Liquor is the alcoholic distillate obtained by the fermented mash of grain molasses, jaggery, or mahua flowers (Madhuca latifolia L.) and contains varying percentage of ethyl alcohol with specific ingredients. Liquors are analyzed and detected as per specifications. Beverages believed to contain ethanol are mentioned in ancient Indian literature dating back to Vedic period around 2000 B. C. . . Two varieties of drinks are described Soma and sura. Soma, the drink of social elite, was credited with positive qualities. On the other hand, Sura a fermented beverage made from rice and sugarcane was consumed by warriors to enhance their valour and courage among other thing.

HPTLC is important analytical separation technique having advantage of simultaneous separation of several samples on single plate needs small amount of developing solvents and can separate milligram amount of sample. Use of automatic sample application device, UV/fluorescent detectors, densitometer scanner (which converts the spot on a layer in to a chromatogram with series of peak) coupled with software enable HPTLC tool to enhance sensitivity of analyte detection ${ }^{2}$. 
Postmortem forensic toxicology frequently finds alcohol both alone and in combination with drugs. Although benzodiazepines are generally considered safe are considered dangerous with alcohol ${ }^{3}$. Effect of oxytocin on lactation in various animals was reported also $^{4-16}$. Estimation of oxytocin in milk by reverse phase high performance liquid chromatography reported in literature ${ }^{17-20}$.

\section{Experimental}

$15.063 \mathrm{~g}$ of sodium dihydrogen orthophosphate dissolved and diluted to $1000 \mathrm{~mL}$ with millipore water

\section{Preparation of oxytocin standard solution}

$17.03 \mathrm{mg}$ of oxytocin standard dissolved and diluted to $100 \mathrm{~mL}$ with solution A. Further $5 \mathrm{~mL}$ of this solution diluted to $50 \mathrm{~mL}$ with solution A. (i.e. $17 \mathrm{ug} / \mathrm{mL}$ )

\section{Preparation of suspected sample solution}

$25 \mathrm{~mL}$ of suspected sample was made acidic to $\mathrm{pH}=3-4$ with acetic acid and then extracted with 2x25 mL dichloromethane: methanol (9:1). Organic layer was filtered and dried over anhydrous sodium sulphate. The extract was evaporated to dryness and dissolved in solution A to a $1 \mathrm{~mL}$.

\section{Preparation phosphomolybdotungstate reagent}

$10.0043 \mathrm{~g}$ of sodium tungstate and $2.5016 \mathrm{~g}$ of sodium molybdate was dissolved in a beaker containing $70 \mathrm{~mL}$ of water, $10 \mathrm{~mL}$ hydrochloric acid and $5 \mathrm{~mL}$ of orthophosphoric acid and the mixture was heated under a reflux for 10 hours. To this solution after cooling $15.0120 \mathrm{~g}$ lithium sulphate, $5 \mathrm{~mL}$ water and $0.20 \mathrm{~mL}$ of bromine was added and solution was boiled to remove excess bromine (about 15 minutes). Care was taken to remove excess bromine by boiling. After cooling the resulting solution was diluted to $100 \mathrm{~mL}$ with water and filtered. The reagent was yellow in colour. If it acquires a greenish tint then it is unsuitable for the use and can be regenerated by boiling with $0.2 \mathrm{~mL}$ of bromine. [Note: Reagent was stored at 2 to $8{ }^{\circ} \mathrm{C}$.

\section{Instrumentation}

Model No.

: AS-30

Make

: DESAGA SARSTEDT-GRUPPPE

Plate reader

: CD 60

\section{Results and Discussion}

Precoated silica gel ${ }^{60} \mathrm{~F}_{254}(20 \times 20 \mathrm{~cm})$ glass plate was previously activated up to $13 \mathrm{~cm}$ by mobile phase glacial acetic acid: water: methanol and dichloromethane (1:6:30:70). Then, oxytocin standard $(17 \mathrm{ug} / \mathrm{mL})$ solution was applied twice on precoated silica gel ${ }^{60} \mathrm{~F}_{254}$ $(20 \times 20 \mathrm{~cm})$ glass plate with the help of applicator (AS-30) using spot length $3 \mathrm{~mm}$. Suspected sample solution prepared in solution A was also applied twice on the same plate with spot length $3 \mathrm{~mm}$. Then plate was developed in above selected up to $13 \mathrm{~cm}$.

After removing the plate it was dried in a stream of cold air for 10 minutes and develops again with with fresh mobile phase for about 30 minutes. After removal of the plate, allow it to dry in a stream of warm air for 10 minutes and spray with phosphomolybdotungstate reagent until the plate appears translucent. Then immediately it was placed in a tank containing 
13.5 $\mathrm{M}$ ammonia for 5 minutes and dried in stream of warm air. The mobile phase showed the separation by using mixture of glacial acetic acid: water: methanol and dichloromethane (1:6:30:70) (Figure 2). The retardation factor $\left(R_{f}\right)$ of oxytocin is -0.75 tallies with the $R_{\mathrm{f}}$ of suspected samples. This confirms the adulteration of oxytocin in the suspected liquors.



Figure 2. HPTLC photograph showing oxytocin spot, I-exhibit no.1, II -exhibit no 2, III-control sample of oxytocin, IV-control sample of oxytocin

\section{Conclusion}

New specific and cost effective solvent system Glacial acetic acid: water: methanol and dichloromethane (1:6:30:70) was found to be useful for the separation and identification of Oxytocin from toddy samples, and also phosphomolybdotungstate specific spray reagent for visulation of oxytocin by HPTLC. Phosphomolybdotungstate spray reagent removes interference of higher alcohols, acids and esters present in illicit liquor samples.

\section{Acknowledgment}

Authors are thankful to Dr. M. K. Malve, Director, Directorate, Forensic Science Laboratories, Mumbai-400098 for kind help in carrying out the work.

\section{References}

1. Chopra R N and Chopra I C, Drug Addiction with Special Reference to India. New Delhi, Council of Scientific and Industrial Research, 1965.

2. Butler William P, Method of Analysis for Alkaloids, Opiates, Marihuana, Barbiturates \& Miscellaneous Drugs, Bureau of Narcotics \& Dangerous Drugs, Department of Justice, US: 1987, 59. 
3. Koski A, Ojanpera I and Vuori E, Alcoholic Clin Exp Res., 2002, 26(7), 956-959; DOI:10.1111/j.1530-0277.2002.tb02627.x

4. $\quad$ Allen J C, J Dairy Sci., 1990, 73(4), 975-984;

DOI:10.3168/jds.S0022-0302(90)78755-3

5. $\quad$ Bruckmaier R M and Blum J W, J Dairy Res., 1996, 63(02), 201-208;

DOI: $10.1017 / S 0022029900031708$

6. $\quad$ Bruckmaier R M, J Dairy Res., 2003, 70(01), 123-126;

DOI:10.1017/S0022029902005940

7. Cowie A T, $J$ Endocr., 1969, 44(3), 437-450; DOI:10.1677/joe.0.0440437

8. Crowley W R and Armstrong W E, Endocrin Rev., 1992, 13(1), 33-65; DOI:10.1210/edrv-13-1-33

9. Donker J D, Koshi J H and Petersen W E, Science, 1954, 119(3080), 67-68; DOI:10.1126/science.119.3080.67

10. Gachev E, Endokrinologie, 1963, 44, 71-74.

11. Gachev E P, C R Acad Bulg Sci., 1971, 24, 543-546.

12. Gopal P K and Gill H S, British J Nutr., 2004, 84, 69-74.

13. Linzell J L and Peaker M, J Physiol., 1971, 216(3), 717-734.

14. Mayer H, Bruckmaier R and Schams D, J Dairy Res., 1991, 58(02), 159-169; DOI:10.1017/S0022029900029708

15. Nickerson T A, Lactose. In: Fundamentals of Dairy Chemistry, Webb B H, Johnson A H and Alford J A, (Eds.), $2^{\text {nd }}$ Ed., AVI Publishing, Westport, CA. 1974, 273-324.

16. Peaker M and Taylor J C, J Physiol., 1975, 253(2), 527-545.

17. Suresh Kumar K, Kavitha M P, Dharuman J and Dhandapani B, Int J ChemTech Res., 2010, 2, 1340-1343.

18. David R Cool and David de Brose, Department of Pharmacology and Toxicology, USA, J Chromatogr B, May 2003.

19. Larson K, Hermann W, Moller P and Sanchez D, J Chromatogr., 1998, 450(1), 71-80; DOI:10.1016/S0021-9673(00)90716-7

20. Sandra Pereira FUKUDA, Salvador Massaguer ROIG and Louis Fransisco PRATA, Correlation Between Acidic Ninhydrin and HPLC Detection Methods to Evaluate Addition of Whey in Milk. Veterinary University, Brazil, EDP Sciences 2004. 